See discussions, stats, and author profiles for this publication at: https://www.researchgate.net/publication/332759115

\title{
Application of the group contribution volume translated Peng-Robinson equation of state to new commercial refrigerant mixtures
}

Article in International Journal of Refrigeration · April 2019

DOI: $10.1016 /$ j.j.jrefrig.2019.04.014

\section{CITATIONS}

6 authors, including:

\section{Ian H. Bell}

National Institute of Standards and Technology

62 PUBLICATIONS 757 CITATIONS

SEE PROFILE

2. Fredrik Haglind

Technical University of Denmark

109 PUBLICATIONS 1,365 CITATIONS

SEE PROFILE

Some of the authors of this publication are also working on these related projects:

Project Thermcyc: Working package on working fluid design View project

Project Organic Rankine Cycle and Scrubber integration View project

\section{READS}

70

2 Maria E. Mondejar

34 PUBLICATIONS 313 CITATIONS

SEE PROFILE 


\title{
Application of the group contribution volume translated Peng-Robinson equation of state to new commercial refrigerant mixtures ${ }^{\vec{t}}$
}

\author{
I. H. Bella,*, J. Welliquet ${ }^{\mathrm{b}}$, M. E. Mondejar ${ }^{\mathrm{c}}$, A. Bazyleva ${ }^{\mathrm{a}}$, S. Quoilin ${ }^{\mathrm{d}}$, F. Haglind ${ }^{\mathrm{c}}$ \\ ${ }^{a}$ Applied Chemicals and Materials Division, National Institute of Standards and Technology, Boulder, CO 80305, USA \\ ${ }^{b}$ Energy Systems Research Unit, University of Liége, Liége, Belgium \\ ${ }^{c}$ Department of Mechanical Engineering, Technical University of Denmark, Building 403, 2800 Kongens Lyngby, Denmark \\ ${ }^{d}$ Department of Mechanical Engineering, KU Leuven, Geel. Kleinhoefstraat 4. 2440 Geel, Belgium
}

\begin{abstract}
This work evaluates the performance of the group contribution volume translated Peng-Robinson model when predicting the vapor-liquid equilibrium and single phase densities of 28 commercial refrigerant mixtures with low global warming potential and zero ozone depletion potential. Cubic equations of state, and particularly the Peng-Robinson equation of state, are widely used in the refrigeration industry due to their easy applicability for new substances, and their low computational time, although generally lower prediction accuracies must be expected compared to multiparameter equations of state. The group contribution volume translated Peng-Robinson equation of state combines the Peng-Robinson equation of state with a new attraction term, improved mixing rules using a group contribution approach, and volume translation. The results are compared with the estimates obtained using the non translated Peng-Robinson equation of state, and a multiparameter equation of state.
\end{abstract}

Keywords: Cubic equation of state, Peng-Robinson, GC-VTPR, UNIFAC, refrigerant mixtures.

\section{Introduction} The current search for sustainable and environmenta
friendly refrigerants is driven by the recent approval of increasingly restrictive regulations that limit the ${ }^{13}$ use of substances with high global warming poten- ${ }^{14}$ tial (GWP), and the need to maintain high process ${ }^{15}$ efficiencies. In this context, mixtures containing new ${ }^{16}$ refrigerants with low GWP are of special importance, ${ }^{17}$ since their use offers new degrees of freedom that ${ }^{18}$

\footnotetext{
Contribution of the National Institute of Standards and Technology, not subject to copyright in the US

${ }^{*}$ Corresponding author

Email addresses: ian.bell@nist.gov (I. H. Bell), j.welliquet@alumni.ulg.ac.be (J. Welliquet), maemmo@mek.dtu.dk (M. E. Mondejar), ala.bazyleva@nist.gov (A. Bazyleva), sylvain.quoilin@kuleuven. be (S. Quoilin), frh@mek.dtu.dk (F. Haglind)
} ally of the thermophysical properties of new refrigerants are scarce, and it is even scarcer for their mixtures. The lack of experimental data makes it unfeasible to develop complex multiparameter equations of state (EoSs) (such as those available in the state of the art thermophysical property library REFPROP (Lemmon et al. 2018) ) and to ensure high accuracy of the predictions. This fact introduces additional uncertainty in the prediction of the performance of new refrigerants, and the evaluation of their prospects as future replacement refrigerants. In this context it is essential to develop mixture models that, requiring little to no experimental data of the novel refrigerants, are able to estimate their thermophysical behavior with sufficient accuracy. 
Cubic equations of state (cEoS) have been widely 40 used in the simulation of chemical industrial pro- 41 cesses and in the oil extraction industry because they 42 require only a very general knowledge of the fluid 43 molecule and allow for fast computational times. Al- 44 though it is well known that cEoS fail in the predic- 45 tion of liquid densities, and near the critical point, 46 as well as in the prediction of properties of polar ${ }_{47}$ substances, a number of new cEoS have been devel- 48 oped in order to improve their accuracy for specific 49 cases. However, when used for the estimation of 50 mixture properties, cEoS require the use of mixing ${ }_{51}$ rules that contain parameters which are commonly 52 fitted from experimental data for specific fluids. This ${ }_{53}$ can represent a problem when one or more of the 54 mixture components is a relatively newly introduced ${ }_{55}$ substance for which there are minimal experimental 56 measurements.

In principle, there are two types of mixing rules 58 for $\mathrm{cEoS}$, which are the van der Waals mixing rules, 59 and the excess Gibbs energy mixing rules. van der 60 Waals mixing rules use the composition and mix-61 ing parameters, which are fitted to experimental data, 62 to estimate the attractive and repulsive terms of the 63 cEoS. The excess Gibbs energy mixing rules inte- 64 grate activity coefficient models into the cEoS, thus 65 allowing for an improved estimation of the vapor- 66 liquid equilibrium properties, especially for polar flu- 67 ids. In order to extend the use of either of these mix- 68 ing models to new refrigerants, it is necessary to be 69 able to predict the mixing parameters or the activ-70 ity coefficients based on a general knowledge of the 71 molecule.

The group contribution volume translated Peng ${ }_{73}$ Robinson equation of state (GC-VTPR EoS) was first 74 proposed by Ahlers and Gmehling (2002a; 2002b $)_{75}$ with the aim of developing a universal, simple and 76 accurate way of estimating the thermophysical be- 77 havior of both polar and non-polar fluids. In its orig- 78 inal form, the GC-VTPR EoS combined the Twualpha function for the attraction term (Twu et al. 1995), the volume translation as proposed by Péneloux et al. (1982), and the modified UNIFAC model (Fredenslund et al., 1975) for the mixing rule. In this way, a general method was introduced to express the interaction between the molecules in the mixture, based only on a functional group contribution approach. With this method, it was not necessary to fit the mixing parameter for each possible molecule pair of newly developed mixtures for which no experimental data was available. Moreover, the volume translation provided a correction to the saturated liquid volume, which is one of the weaknesses of cubic EoS. A similar approach was presented by Jaubert and Mutelet (2004), who presented the PPR78 EoS as a combination of the Peng-Robinson EoS with a group contribution method for the estimation of the mixing parameters using a van Laar type activity-coefficient model.

A number of works have been published on the use of the GC-VTPR EoS, most of them focused on the prediction of different mixtures of organic compounds (e.g. alkanes, alcohols, acids) (Schmid and Gmehling, 2016), showing good agreement with experimental results. However, the ability of the GCVTPR EoS to reproduce the properties of refrigerant mixtures, including new halogenated olefins, has not been studied so far. Only Qian et al. (2017) considered refrigerants in their extension of the work of the PPR78 EoS to predict the mixing parameters of some HFOs blends. Nevertheless, not all the functional groups needed to define the refrigerants considered in this work were defined in Qian et al. (2017), and the considered mixing rule was the classical van der Waals rule.

This work presents an assessment of the accuracy of the GC-VTPR EoS to predict the saturation properties of a number of commercial refrigerant mixtures with low GWP and zero ozone depletion poten- 
tial (ODP). The predictive capacity of the GC-VTPR 40 EoS is analyzed over different pressure and temper- 4 ature ranges, and is compared with that of the con- 42 ventional Peng-Robinson equation of state (PR EoS), 43 the translated Peng-Robinson equation of state (PR+ 44 EoS), and a multi-parameter Helmholtz-energy-explicit EoS (HEOS). The objectives of this work are:

- To quantify the accuracy of the GC-VTPR $\operatorname{EoS}^{46}$ when predicting the saturated pressures and sat ${ }^{47}$ urated liquid and vapor densities of the selected ${ }^{48}$ refrigerant mixtures.

- To present the fitted values of the interaction ${ }_{51}$ parameters of the modified UNIFAC needed ${ }_{52}$ for the representation of a number of refriger- 53 ants in the GC-VTPR model.

- To provide the research and the industrial community with an assessment on the suitability of GC-VTPR EoS for the study of new refrigerant mixtures.

- To describe in detail the algorithm used for fitting the interaction parameters.

This work presents a number of novel contribu- ${ }^{60}$ tions. First, the ability of the GC-VTPR EoS to pre- ${ }^{6}$ dict the behavior of refrigerant mixtures containing ${ }^{62}$ the new low-GWP hydrofluoroolefins, dimethyl ether, hydrofluorocarbons, and hydrocarbons, was thoroughly evaluated. Second, the values of the group surface areas of the UNIFAC model that were missing for spe- ${ }^{66}$ cific functional groups were fitted based on the complete dataset of available experimental data. Third, indications on the use of the GC-VTPR EoS for the studied mixtures, based on the analyzed relative de- ${ }^{70}$ viations of the predictions for the evaluated properties, are given.

The outline of this paper is as follows: in Sec- ${ }^{73}$ tion 2. 2, the GC-VTPR EoS is introduced. In Section 3 the binary ${ }^{75}$ mixtures analyzed in this work are selected based on ${ }^{76}$ their importance for the industry. Section 4 explains ${ }^{77}$ the methods used to fit the parameters of the mixing model. Section 5 presents the results of the predictions of the GC-VTPR EoS for different properties, and selected mixtures. Concluding remarks are given in Section 6 ,

\section{Thermodynamic Modeling}

\subsection{Cubic equations of state}

An EoS relates a number of thermodynamic variables, defining the state of a substance so that any other thermodynamic property can be derived from it. A cEoS, normally expressed in a pressure-explicit form, gives the pressure of a fluid $p$ as a function of the temperature $T$ and molar volume $v$, and can be expressed as a polynomial of the third order in the molar volume. This type of equation is generally referred to as $p-v-T$ EoS and links the liquid and vapor phases with a single equation (Frey et al. 2007).

The first cubic equation of state was developed by van der Waals (1873), and is expressed as follows:

$$
\left(p+\frac{a}{v^{2}}\right)(v-b)=R T
$$

where the $a$ and $b$ parameters are functions of the critical pressure and critical temperature of the fluid, and $R$ is the ideal gas constant. The parameter $a$ is called the attraction term, and $b$ is the covolume (or effective molecular volume) as they account, respectively, for the attraction and repulsion forces between the molecules of the fluid. One of the main advantages of this EoS, which is shared by many other $\mathrm{cEoS}$, is that only the knowledge of the critical temperature $T_{c}$ and critical pressure $p_{c}$ are required to define the model; these properties are frequently tabulated in handbooks and databases for a large number of substances.

Since the publication of this first $\mathrm{cEoS}$, a number of modifications have been applied to the model in order to improve its prediction ability (Valderrama, 2003; Wei and Sadus, 2000; Lopez-Echeverry et al. 2017). Most of these improvements modify the attraction term $a$ and the repulsion term $b$ and express 
them as functions of other variables. One of the most ${ }_{37}$ important modifications consists of the addition of a temperature dependent function to the attractive term, the so-called alpha function. In this way, the parameter $a$ is generally expressed as a constant part $a_{c}$ (a function only of tabulated critical parameters of the fluid) multiplied by a temperature dependent term $\alpha\left(T_{\mathrm{r}}\right)$, where $T_{\mathrm{r}}$ is the reduced temperature $T_{\mathrm{r}}=$ $T / T_{\mathrm{c}}$. Examples of equations applying a temperaturedependent attraction term are the Soave-Redlich-Kwon (SRK) EoS (Soave, 1972), and the Peng-Robinson (PR) EoS (Peng and Robinson, 1976).

\subsubsection{Peng-Robinson equation of state}

As described in Poling et al. (2001), the fam-39 ily tree of cEoS can be cast into a common struc- 40 ture, where the different modifications of the attrac- 41 tion term are tabulated with adjustable parameters. 42 Bell and Jäger (2016) carried out a similar exercise, 43 for the SRK EoS, PR EoS, and the van der Waals 44 EoS, with the aim of expressing the analytic deriva- 45 tives of these EoS in a form compatible with the multi $* 6$ parameter Helmholtz-energy-explicit EoS. In this franrework, the cEoS is expressed in the following form: 48

$$
p=\frac{R T}{v-b}-\frac{a(T)}{\left(v+\Delta_{1} b\right)\left(v+\Delta_{2} b\right)}
$$

where $\Delta_{1}$ and $\Delta_{2}$ are different for each EoS, being $\Delta_{1}=1+\sqrt{2}$ and $\Delta_{2}=1-\sqrt{2}$ for the PR EoS. The PR EoS is a modification of the SRK EoS that allows for better predictions of molar volumes in the liquid region and a better representation of the vaporliquid equilibrium for many mixtures (Valderrama, 2003). These features have made the PR EoS into one of the most used cEoS today. Although other cEoS have been developed, none has demonstrated $\mathrm{a}^{52}$ clear general advantage in thermodynamic property ${ }^{53}$ predictions (Frey et al., 2007).

The PR EoS for a pure fluid, expressed explicitly ${ }^{55}$ in terms of pressure, has the following form:

$$
p=\frac{R T}{v-b}-\frac{a_{\mathrm{c}} \alpha\left(T_{\mathrm{r}}, \omega\right)}{v(v+b)+b(v-b)}
$$

where the parameters are expressed as follows:

$$
\begin{aligned}
a_{\mathrm{c}} & =0.45724\left(\frac{R^{2} T_{\mathrm{c}}^{2}}{p_{\mathrm{c}}}\right) \\
b & =0.07780\left(\frac{R T_{\mathrm{c}}}{p_{\mathrm{c}}}\right) \\
\alpha\left(T_{\mathrm{r}}, \omega\right) & =\left[1+m(\omega)\left(1-\sqrt{T_{\mathrm{r}}}\right)\right]^{2}
\end{aligned}
$$

where the term $m$ is a function of the acentric factor and is given as follows (for $\omega \leq 0.491$ ):

$$
m(\omega)=0.37464+1.54226 \omega-0.26992 \omega^{2} .
$$

s8 For $\omega>0.491$, the alternative form in Peng and Robinson (1976) is recommended.

The parameters $a_{\mathrm{c}}$ and $b$ as defined here are fluid dependent. In the case of fluid mixtures, a mixing rule is necessary. See the work by Valderrama (2003) for a list of common mixing rules. The classical mixing rule is that of van der Waals, which can be augmented by one $\left(k_{i j}\right)$ or two $\left(k_{i j}\right.$ and $\left.l_{i j}\right)$ adjustable parameters. These parameters need to be fitted to ex- perimental data for each fluid pair. In the scope of this work, the van der Waals mixing rule without adjustable parameters (equivalent to $k_{i j}=0$ and $l i j=0$ ) is used for the Peng-Robinson (PR) model:

$$
\begin{aligned}
a_{\mathrm{c}} & =\sum_{i} \sum_{j} x_{i} x_{j} a_{i j} ; & a_{i j}=\sqrt{a_{c, i} a_{c, j}} \\
b & =\sum_{i} \sum_{j} x_{i} x_{j} b_{i j} ; & b_{i j}=\frac{b_{i}+b_{j}}{2}
\end{aligned}
$$

\subsection{Volume translation}

As mentioned in the previous section, cEoS generally yield poor predictions of liquid phase densities. For instance, the conventional PR EoS yields errors of more than $17 \%$ in the prediction of the density of ordinary water at $298 \mathrm{~K}$ and 1 bar. A standard approach to address this problem is to apply a correction to the liquid volume, which has nearly no impact on the gas region volumes. 
The correction (or translation) term $c$, which is applied as in $v_{\text {corr }}=v_{\text {EoS }}+c$ equals the difference between the predicted and experimental saturated liquid molar volumes at the reduced temperature $T_{\mathrm{r}}=$ 0.7 (Schmid and Gmehling, 2012) as:

$$
c=\left.\left(v_{\exp }-v_{\mathrm{cEoS}}\right)\right|_{T_{\mathrm{r}}=0.7} .
$$

Based on this term, the volume translated PengRobinson equation of state $(\mathrm{PR}+\mathrm{EoS})$ can be rewrit- ${ }_{40}$ ten as:

$$
p=\frac{R T}{v+c-b}-\frac{a_{\mathrm{c}} \alpha\left(T_{\mathrm{r}}, \omega\right)}{(v+c)(v+c+b)+b(v+c-b)}
$$

This approach yields good results, although tem- 46 perature dependent volume translations could also be 47 used in order to enhance the accuracy near the criti- 48 cal point, or for specific fluids (Ji and Lempe, 1997). 49 The work of Jaubert et al. (2016) and Privat et al. 50 (2016) investigates the impact of volume translation 51 on the other thermodynamic properties that can be 52 obtained from an equation of state.

\subsection{The group contribution volume translated Peng- Robinson equation of state}

The modification of the PR EoS proposed by Ahlers and Gmehling(2002a; 2002b) consists of a combination of several of the above mentioned improvements, with the aim of developing a universal, accurate model for the prediction of thermophysical properties of fluids. This modification is, in fact a group contribution volume translated version of the PR EoS, and will be referred to as GC-VTPR EoS in this manuscript for simplicity.

As explained in the previous section, this new EoS applies a constant translation to the molar volume to improve the accuracy of the predictions in the liquid region. Moreover, the attraction term used is the one presented by Twu et al. (1991), which is expressed as follows:

$$
\alpha\left(T_{\mathrm{r}}, \omega\right)=T_{\mathrm{r}}^{N(M-1)} \exp \left[L\left(1-T_{\mathrm{r}}^{M N}\right)\right],
$$

where the parameters $L, M$ and $N$ have to be fit experimentally for each pure substance. The values of these parameters for the fluids considered in this work can be found in Appendix A. Although the use of the Mathias-Copeman alpha function (Mathias and Copeman, 1983) could be also a possibility, the consistency checks of Le Guennec et al. (2016a) suggest that the Twu alpha function should be preferred.

Finally, the group contribution part of the EoS comes from the use of the UNIFAC group contribution method to predict the activity coefficients of the excess Gibbs energy mixing rule. In this sense, while a simple arithmetic mixing rule is used for the covolume $b$, as shown in Eqs. 13 and 14, a mixing rule, which is based on the Gibbs energy, is used for the attractive term $a$ as in Eq. (15) (Schmid and Gmehling, 2012; Chen et al., 2002):

$$
\begin{gathered}
b=\sum_{i} \sum_{j} x_{i} x_{j} b_{i j} \\
b_{i j}=\left(\frac{b_{i i}^{\frac{3}{4}}+b_{j j}^{\frac{3}{4}}}{2}\right)^{\frac{4}{3}} \\
a\left(T_{\mathrm{r}}, \omega\right)=b \sum_{i} x_{i} \frac{a_{i i}}{b_{i i}}+\frac{g^{E, R}}{-0.53087 \mathrm{~J} \mathrm{~mol}^{-1}} .
\end{gathered}
$$

The prediction of the residual part of the Gibbs energy $g^{\mathrm{E}, \mathrm{R}}$ by a group contribution approach will be further discussed in detail in the next section. To conclude, the mixing rule used for the volume translation parameter $c$ is given as follows:

$$
c=\sum_{i} x_{i} c_{i}
$$




\subsubsection{The Universal Quasichemical Functional Group Activity Coefficients}

The residual part of the excess Gibbs energy from Eq. (15) is defined through the activity coefficients as ${ }^{30}$ follows:

$$
g^{\mathrm{E}, \mathrm{R}}=R T \sum_{i} x_{i} \ln \gamma_{i}^{\mathrm{R}},
$$

Here $g^{\mathrm{E}, \mathrm{R}}$ represents the excess molar Gibbs energy and $\gamma_{i}^{\mathrm{R}}$ is the residual part of the activity coefficient of component $i$. The universal functional activity coefficient (UNIFAC) is a semiempirical method ${ }_{34}$ that predicts activity coefficients of fluids, based on 35 their molecular structure, by using contributions for 36 each of the interactions between pairs of structural ${ }_{37}$ groups in non-electrolyte systems, which are fitted to 38 experimental data (Poling et al., 2001). The UNIFAC ${ }_{39}$ group contribution model was develop to predict the vapor-liquid equilibrium of mixtures, by considering them as mixtures of structural groups, instead of mixtures of components. This approach lead to 40 a general formulation that allowed the estimation of 41 the vapor-liquid equilibrium of most of the systems 42 of commercial interest.

The value of the activity coefficient of a given 44 component in a mixture can be decomposed into a 45 combinatorial and a residual part as in Eq. 18 (Poling et al., 2001):

$$
\ln \gamma_{i}=\ln \gamma_{i}^{\mathrm{C}}+\ln \gamma_{i}^{\mathrm{R}}
$$

The combinatorial part is defined as:

$$
\begin{gathered}
\ln \gamma_{i}^{\mathrm{C}}=\ln \frac{\phi_{i}}{x_{i}}+\frac{z}{2} q_{i} \ln \frac{\theta_{i}}{\phi_{i}}+l_{i}-\frac{\phi_{i}}{x_{i}} \sum_{j} x_{j} l_{j} \\
l_{i}=\frac{z}{2}\left(r_{i}-q_{i}\right)-\left(r_{i}-1\right) .
\end{gathered}
$$

Here $x_{i}$ is the molar fraction of the component 49 $i, z$ refers to the coordination number (usually equal 50 to 10$), \phi_{i}$ is the segment fraction, $\theta_{i}$ is the area fraction, $r_{i}$ is the molecular van der Waals volume, and $q_{i}$ is the molecular surface area. Each of the last four variables are defined as follows:

$$
\begin{gathered}
\theta_{i}=\frac{q_{i} x_{i}}{\sum_{j} q_{j} x_{j}} \\
\phi_{i}=\frac{r_{i} x_{i}}{\sum_{j} r_{j} x_{j}} \\
r_{i}=\sum_{k} v_{k}^{(i)} R_{k}
\end{gathered}
$$

$q_{i}=\sum_{k} v_{k}^{(i)} Q_{k}$

where $v_{k}^{(i)}$ is the number of groups of type $k$ in molecule $i$. The van der Waals volume $R_{k}$ and surface area $Q_{k}$ are tabulated for a wide range of structural groups in Poling et al. (2001, Table 8.23).

The residual part of the activity coefficient is expressed as:

$$
\ln \gamma_{i}^{\mathrm{R}}=\sum_{k} v_{k}^{(i)}\left(\ln \Gamma_{k}-\ln \Gamma_{k}^{(i)}\right)
$$

where $\Gamma_{k}$ is the residual activity coefficient of group $k$, and $\Gamma_{k}^{(i)}$ is the pure fluid group residual activity coefficient of group $k$ (the residual activity coefficient of group $k$ in a reference solution containing only molecules of type $i$ ). These residuals can be obtained from Eq. (28), as:

$$
\begin{gathered}
\ln \Gamma_{k}=Q_{k}\left[1-\ln \left(\sum_{m} \theta_{m} \psi_{m k}\right)-\sum_{m} \frac{\theta_{m} \psi_{m k}}{\sum_{n} \theta_{n} \psi_{n m}}\right] \\
\theta_{m}=\frac{Q_{m} X_{m}}{\sum_{n} Q_{n} X_{n}} \\
\psi_{m n}=\exp \left(-\frac{a_{m n}+b_{m n} T+c_{m n} T^{2}}{T}\right),
\end{gathered}
$$

Here $\theta_{m}$ is the area fraction of group $m, \psi_{m n}$ is the group interaction parameter, $X_{m}$ is the mole fraction of the group $m$ in the mixture, and $a_{m n}, b_{m n}$ and $c_{m n}$ are group interaction parameters obtained by fitting experimental data and are tabulated in databases. 
${ }^{1}$ The refrigerant nomenclature used in this work corresponds to the ASHRAE 34 standard (ASHRAE, 2016); the ISO ${ }^{56}$ 817 standard ISO 817:2014 (en) is substantially similar.

\section{Selected mixtures}

The Air-Conditioning, Heating, and Refrigeration Institute (AHRI) has recently identified a number of mixtures of hydrofluorocarbons (HFCs) and hydrofluoroolefins (HFO) to replace the HFCs with high GWP that are currently in use (e.g., R-134a, R-404A, R-410A 1). These proposed mixtures contain at least two of the following pure refrigerants: R-32, R-125, R-134a, R-152a, R-1234yf, $n$-butane, isobutane, and dimethyl ether. Following this recommendation, several commercial mixtures containing these components are available in the market (MotaBabiloni et al., 2015):

- R-134a + R-1234yf: D-4Y, XP-10

- R-32 + R-1234yf: D2Y60, DR-5

Several commercial refrigerant families such as $\mathrm{R}^{-{ }^{36}}$ 407 (R-32/R-125/R-134a), R-417 (R-125/R-134a/ $n^{-{ }^{37}}$ butane), R-422 (R-125/R-134a/isobutane), and R-451 ${ }^{38}$ (R-1234yf/R-134a) are relevant for refrigeration and heat pump applications. Moreover, the use of hydrocarbons as refrigerants is regaining interest as they ${ }^{41}$ comply with the recent environmental regulations on 42 GWP, while having a low cost, though they do in- 43 troduce some flammability concerns. The flammable compound dimethyl ether (DME) has also been pro- ${ }^{44}$ posed as an alternative refrigerant given its good heat ${ }^{45}$ transfer properties, high availability and low GWP ${ }^{46}$ (Ben Adamson and Airah, 1998).

In this work, we selected a set of binary mix- 48 tures for the evaluation of the performance of the 49 GC-VTPR EoS based on the aforementioned recom- 50 mendations, and on the availability of experimental data. The selected mixtures are summarized in Ta- ${ }_{51}$ ble 1 , and comprise a set of binary mixtures containing the above mentioned components, with variable ${ }^{52}$ compositions.
Table 1: Binary refrigerant mixtures included in this work. In each cell, the numerator is the number of experimental vaporliquid equilibrium data points (PTXY or bubble-point pressure or dew-point pressure) and the denominator gives in parentheses the numbers of saturated liquid and vapor density experimental data points, respectively.

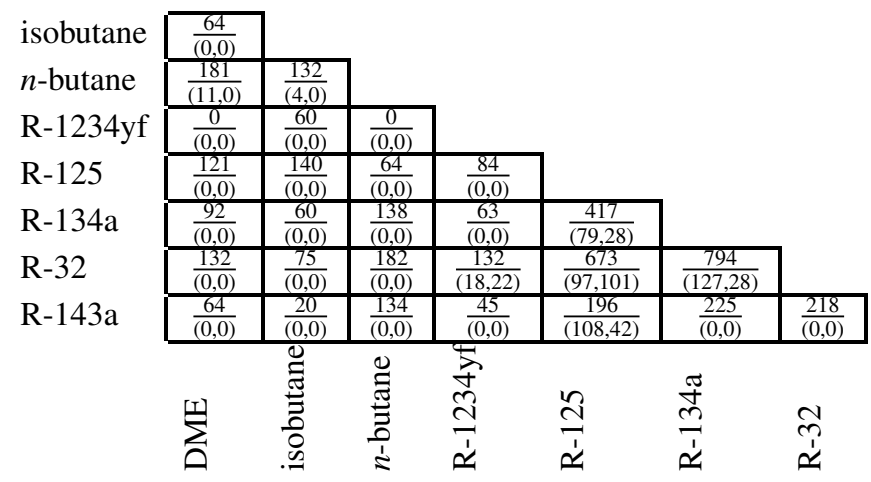

\subsection{Experimental database}

Data provided via the NIST ThermoData Engine \#103b version 10.1 were used in this work for the evaluation of the performance of the GC-VTPR EoS. The database contains experimental data of pure fluids and mixtures collected from publications. Three main data sets were used in this work:

- Vapor-liquid equilibrium data containing the pressure, temperature, and molar fraction of the components for bubble and/or dew points.

- Density data containing the specific volume, pressure, temperature, and molar fraction in the liquid and/or gas phase, as well as for bubble and/or dew points.

- Pure fluid saturated liquid density data, for the computation of the volume translation term $c$ of Eq. (16).

\section{Parameter fitting for the GC-VTPR EoS}

In order to estimate the activity coefficients for each selected mixture according to Eqs. (18) to (28), it is first necessary to decompose each of the components into structural groups that are covered by the database of group parameters. In this work, the group decomposition was inspired by the groups defined by Gmehling (1985), for which the revised and 
Table 2: Molecules and secondary group decomposition of the components of the studied mixtures, derived from the group ${ }^{11}$ decompositions of Gmehling (1985). The group indices corre- 12 spond to the subgroup indices $s g i$ and are defined in Table 3

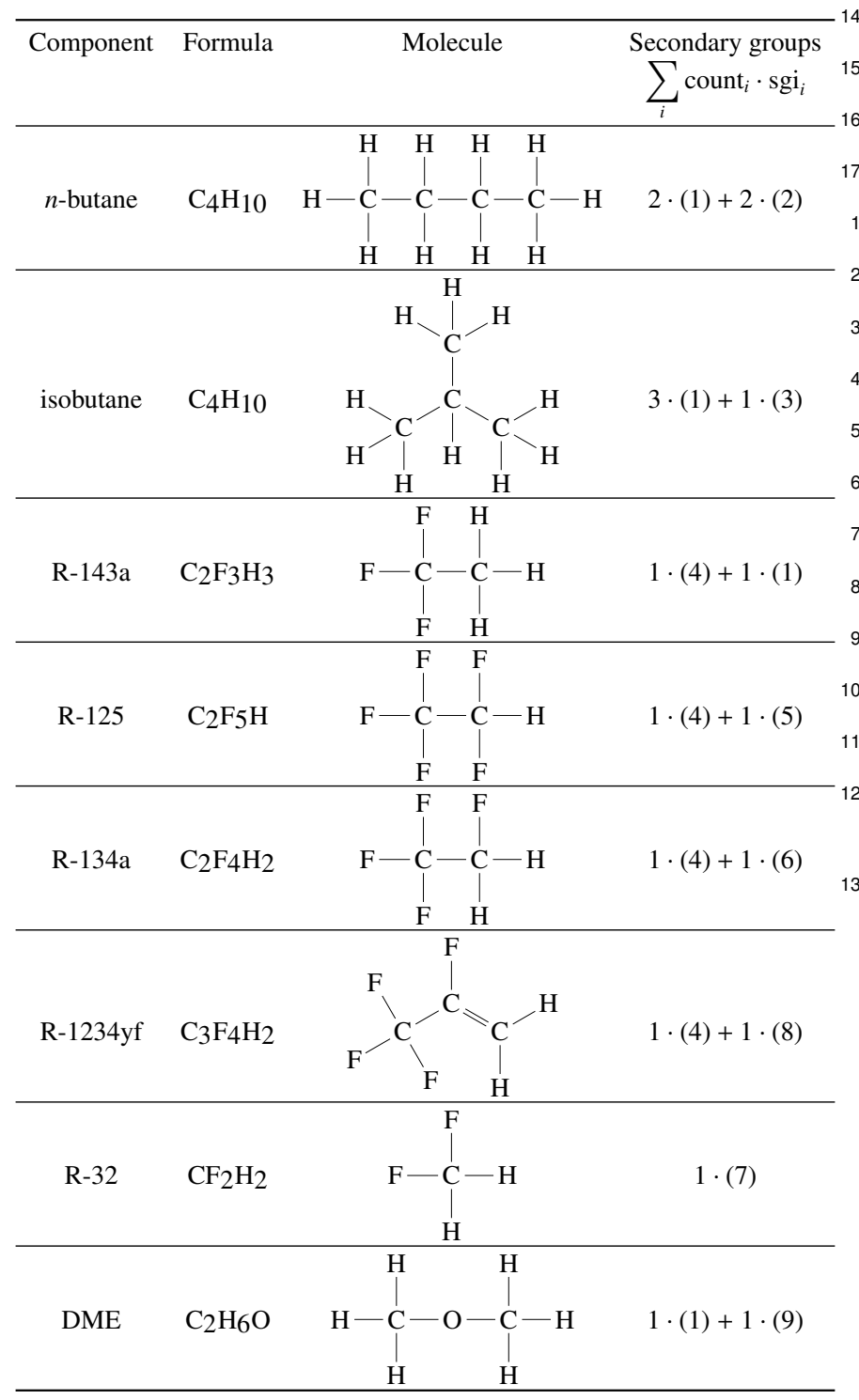

updated UNIFAC parameters are available. The re- 4 frigerant R-32 could not be decomposed through the 5 use of the available groups, and was therefore given 6 its own group. The group decompositions of the con- 7 sidered fluids are described in Table 2, and once spec- 8 ified, were not changed.

\section{.} .

$$
\text { and }
$$

16$$
4
$$$$
5 \text { gro }
$$$$
6 \quad \text { A }
$$$$
7 \text { aWO }
$$$$
3 \text { et }
$$
culated by an additive scheme as detailed in the supplemental material that was based on the numerical values of group surface areas of Bondi (1968). This method provides the values of the van der Waals surface areas of the groups in $\mathrm{cm}^{2} / \mathrm{mol}$, which are converted to normalized surface areas $Q_{k}$ by dividing by the surface area of a standard segment (a methylene group in polymethylene) given as $2.5 \times 10^{9} \mathrm{~cm}^{2} / \mathrm{mol}$ (Abrams and Prausnitz, 1975, Appendix B). Previous works (Schmid and Gmehling, 2012, 2016, Schmid et al. 2014) suggest that the best approach to determine the group surface areas is empirical fitting, but we did not follow that recommendation because some of the $Q_{k}$ values obtained with empirical fitting can be non-physical if not properly constrained.

\subsection{Fitting algorithm}

In the fitting campaign, only vapor-liquid equilibrium data for which the composition of both of the co-existing phases were known were considered. For phases in equilibrium, the chemical potential of all components in all phases must be equal. The equality of chemical potentials can be expressed as:

$$
\mu_{i}^{\prime}\left(T, p, \vec{x}^{\prime}\right)=\mu_{i}^{\prime \prime}\left(T, p, \vec{x}^{\prime \prime}\right)
$$

where $\mu_{i}^{\prime}$ and $\mu_{i}^{\prime \prime}$ are the chemical potentials of species $i$ in the saturated liquid and vapor, respectively, and $\vec{x}^{\prime}$ and $\vec{x}^{\prime \prime}$ are the compositions of the liquid and vapor phases, respectively. This equality can be shown (Kunz et al., 2007, pp. 58-59) to be equal to the equality of fugacity coefficients times their respec- 
tive mole fraction, as:

$$
x_{i}^{\prime} \varphi_{i}^{\prime}\left(T, p, \vec{x}^{\prime}\right)=x_{i}^{\prime \prime} \varphi_{i}^{\prime \prime}\left(T, p, \vec{x}^{\prime \prime}\right)
$$

which is equivalent (from $f_{i}=x_{i} p \varphi_{i}$ ) to the fugacities ${ }_{36}$ of all components in all phases being equal, as:

$$
f_{i}^{\prime}\left(T, p, \vec{x}^{\prime}\right)=f_{i}^{\prime \prime}\left(T, p, \vec{x}^{\prime \prime}\right)
$$

The goal of the optimizer is then to best satisfy ${ }^{40}$ the phase equilibrium conditions for all of the exper- ${ }^{41}$ imental data points by adjusting the group surface areas and interaction parameters. For the $k$-th experimental data point, we have the expense contribution as follows:

$e_{k}^{2}=\sum_{i=0}^{1}\left[\ln \varphi_{i}^{\prime}\left(T, p, \vec{x}^{\prime}\right)-\ln \varphi_{i}^{\prime \prime}\left(T, p, \vec{x}^{\prime \prime}\right)-\ln \left(\frac{\vec{x}_{i}^{\prime}}{\vec{x}_{i}^{\prime}}\right)\right]^{2}$.

The cost function to be minimized by modifying the group-group interaction parameters is the summation of the weighted expense contributions as:

$$
\operatorname{COST}\left(\vec{a}_{i j}, \vec{a}_{j i}\right)=\sum_{k} w_{k} e_{k}
$$

40 ${ }^{4}$ normal font were directly obtained from Poling et al. (2001) and the values in bold font were obtained from the additive scheme detailed in the supplemental material based on the work of Bondi (1968).

\begin{tabular}{cccl}
\hline \multicolumn{2}{c}{ Group number } & & UNIFAC \\
Main & Subgroup & Formula & $Q[-]$ \\
\hline \multirow{2}{*}{1} & 1 & $-\mathrm{CH}_{3}$ & 0.848 \\
& 2 & $-\mathrm{CH}_{2}-$ & 0.540 \\
& 3 & $-\mathrm{CH}<$ & 0.228 \\
\hline \multirow{2}{*}{2} & 4 & $-\mathrm{CF}_{3}$ & 1.380 \\
& 5 & $-\mathrm{HCF}_{2}$ & $\mathbf{1 . 1 0 8}$ \\
& 6 & $-\mathrm{CFH}_{2}$ & $\mathbf{0 . 9 8 0}$ \\
\hline 3 & 7 & $\mathrm{CF}_{2} \mathrm{H}_{2}$ & $\mathbf{1 . 4 2 0}$ \\
\hline 4 & 8 & $-\mathrm{CF}_{2} \mathrm{CH}_{2}$ & $\mathbf{1 . 4 2 8}$ \\
\hline 5 & 9 & $-\mathrm{OCH}_{3}$ & 1.088 \\
\hline
\end{tabular}

\section{Results}

In this section, the performance of the GC-VTPR EoS is compared to experimental data and to other equations of state. These comparison EoS are the reference multi-fluid equation of state, as implemented in NIST REFPROP (Lemmon et al., 2018) library and the Peng-Robinson EoS without volume translation. For the PR EoS, the implementation of CoolProp (Bell et al., 2014) is used. This analysis allows for a comparison of the performance of the GCVTPR EoS with that of the most accurate mixture models available in the literature. The comparison 
presented in this section is performed in terms of rel- 43 ative deviations from the experimental data. The per- ${ }_{44}$ centage relative deviation of an EoS prediction of $\mathrm{a}_{45}$ parameter $\chi$ with respect to the experimental value is ${ }_{46}$ defined as follows:

$$
R D=100 \times\left(\frac{\chi_{\text {calc }}-\chi_{\exp }}{\chi_{\exp }}\right)
$$
sion of the fidelity of the model to the experimental vapor-liquid equilibrium data of the mixture. As described in the literature (Jaubert et al., 2016, Privat $_{54}$ et al., 2016) and as discussed above, the addition of Péneloux-style volume translation does not shift the phase equilibrium, and therefore, the effects of the GC-VTPR model on the VLE data representation can be considered in two parts: i) the impact of the fitted ${ }_{59}$ parameters on the representation of the VLE data ii) ${ }_{60}$ the volume-translated VLE data for the equilibrium phase densities.

All the figures depicting the percentage RD for the different properties and for all the studied mixtures are available in the Supporting Information. In the following sections, only the most representative figures for each case are shown. These figures are classified into three types depending on the way RD 8 are depicted, and are explained below:

- Violin plots: the distribution of the deviation ${ }^{10}$ in a similar manner to a histogram. The lower ${ }^{11}$ and upper bars represent the minimal and max- ${ }^{12}$ imal values, respectively. The middle bar rep- ${ }^{13}$ resents the median.

- Composition dependency plots: the relative de-16 viation versus the molar fraction of the first component of the mixture, which allows for an assessment of how the composition affects the accuracy of the EoS mixing rule.

- Temperature dependency plots: they represent the influence of temperature on the RD, in order to show potential temperature effects on the accuracy of the EoS.

\subsection{Vapor-Liquid Equilibrium}

Figure 1 and Fig. 2 present the pressure-composition isotherms for the mixtures R-125 + R-134a and isobutane + R-134a, respectively, as illustrative cases. Additional results for all the binary mixtures considered are available in the Supporting Information. The predicted values of the bubble and dew pressures for the mixture R-125 + R-134a are in good agreement with the available experimental values over the entire temperature range. However, a different behavior can be observed for the mixture isobutane $+\mathrm{R}-134 \mathrm{a}$. This mixture was chosen as a representative of the predictive performance of the GC-VTPR EoS, as it presents azeotropic behavior at low molar fractions of isobutane. As it can be seen, while the predicted values at high temperatures match reasonably well the experimental bubble point data, the calculated values at low temperatures underestimate the bubble point pressure near the azeotrope.

The strength of the thermodynamic correction that the excess Gibbs energy contribution must provide is highly dependent on the similarity of the components forming the binary mixture and whether the mixture is likely to form azeotropes. In the case of $n$-butane + isobutane, for instance, all groups in the mixture are in the first (mgi=1) main group, and therefore, the excess Gibbs contribution $g^{\mathrm{E}}$ is by definition zero. On the other hand, for binary mixtures that have cross-main-group binary interactions (isobutane + R-134a), the excess Gibbs energy contribution shifts the mixture thermodynamics. Figure 2 demonstrates that the model is able to capture strong positive-pressure azeotropes (which occur frequently in binary mixtures of refrigerant-like fluids). 


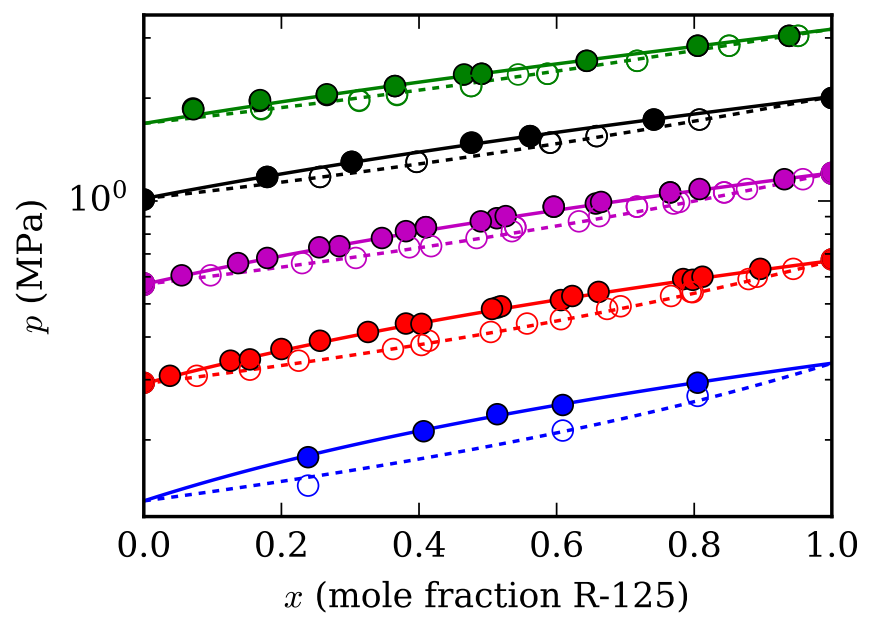

Figure 1: Selected pressure-composition isotherms $\left(253.1{ }^{31}\right.$ 273.1, 293.1, 313.1, 333.1 K) for the mixture R-125 + R-134a 32 versus the mole fraction of R-125 with the GC-VTPR model in this work: $\bullet$ bubble point experimental data; $\circ$ dew point experimental data; - calculated bubble point; - - - calculated dew ${ }^{34}$ point. Experimental data points are taken from the literature 35 (Kleemiss, 1997, Kato and Nishiumi, 2006, Higuchi and Hi- ${ }_{36}$ gashi 1995: Benmansour and Richon, 1999; Widiatmo et al., 1997; Nagel and Bier. 1995; Holcomb et al., 1998; Higashi, ${ }^{37}$ 1999a; Kobayashi and Nishiumi, 1998, Kim and Park, 1999, 38 Nishiumi and Ohno, 2000)

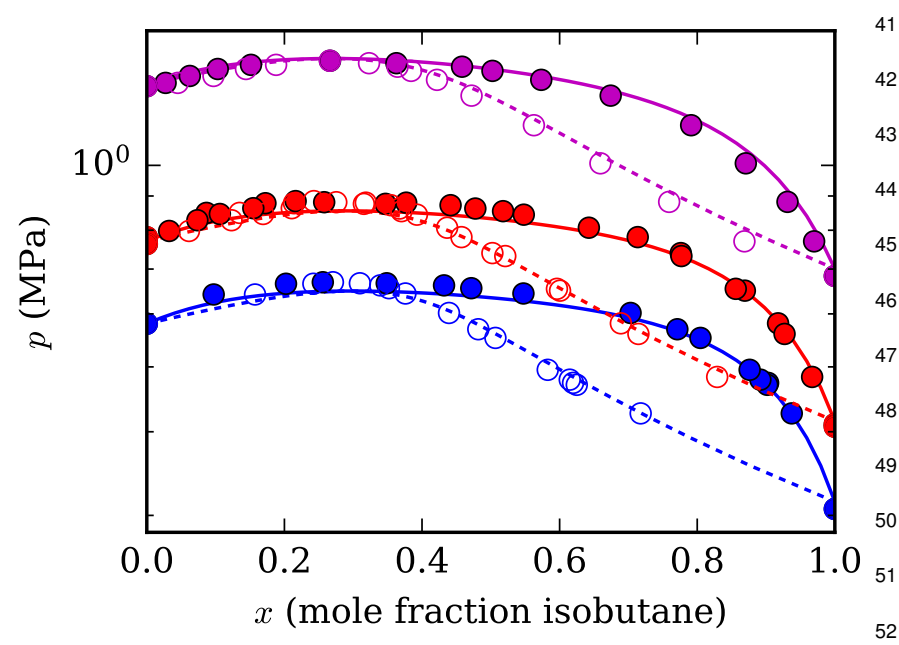

Figure 2: Selected pressure-composition isotherms (293.66, 53 303.2 $323.2 \mathrm{~K}$ ) for the mixture isobutane + R-134a versus the mole fraction of isobutane with the GC-VTPR model in this work: • experimental bubble point; $\circ$ experimental dew point; ${ }^{55}$ - calculated bubble point; - - - calculated dew point. Ex- 56 perimental data points are taken from the literature (Lim et al. 2000; Bobbo et al., 1998)

also be considered as two separate measurements, one for which the mixture is at the bubble-point (the liquid mixture at the bulk composition is in equilibrium with the incipient vapor phase), and another at the dew point (the gaseous mixture at the bulk composition is in equilibrium with the incipient liquid phase). Therefore, although the fitting campaign considered only PTXY data, the analysis of the mixture models considers bubble point and dew point data individually. Here we consider the binary mixture of DME $+n$-butane as an illustrative case of the analysis of the phase equilibrium pressures. We compare the model predictions of phase equilibrium pressure with those of Peng-Robinson, and the reference multiparameter model implemented in the industry standard NIST REFPROP library (Lemmon et al., 2018).

Although deviations in pressure are commonly presented in the literature (and will be here also), the deviation in phase equilibrium pressure is an imperfect metric to capture the "goodness" of the model. This is because as the VLE isotherms become very steep ( $|\mathrm{d} p / \mathrm{d} x|$ becomes large along the VLE isotherm), it is no longer relevant to talk about deviations in pressure; it is better to talk about the orthogonal distance of the experimental data point from the VLE isotherm. Nonetheless, the deviation in pressure is an accessible metric for "quality-of-fit", and particularly for mixtures with slender VLE "lenses", pressure deviations are meaningful.

Figure 3 and Fig. 4 present the results for the mixture of isobutane + R-125; this is one of the mixtures with the largest worst-case relative deviations in saturation pressure (with some bubble-point pressure deviations greater than $30 \%$ ). Figure 3 presents pressure-composition isotherms for the mixture isobutane + R-125 and in Fig. 4, the relative deviations for the bubble-point and dew-point pressures are shown for each of the EOS, as well as the composition and temperature dependence of the deviations of the models. One challenge with this mixture is that all the available PTXY data used to fit this mixture model were above $293 \mathrm{~K}$, therefore the poor fidelity of this 
model for temperatures below $293 \mathrm{~K}$ should not be considered as indictment of the general modeling approach, rather a demonstration of the challenges to obtain the correct extrapolation behavior. For bubblepoint pressures (left side of the figure), the mean absolute error for REFPROP is smallest in magnitude (2.8\%), followed by GC-VTPR (9.2\%) and PengRobinson (28.7\%). The pure fluid endpoints at $x_{1}=$ 0 and $x_{1}=1$ are governed by the behavior of the $\alpha$ function and the Twu parameters; for a pure fluid the UNIFAC contribution is zero.

At low temperatures, all of the mixture models deviate strongly from the experimental data. This can be partially explained by the data that were included in the fitting of the interaction parameters in NIST REFPROP. The binary interaction parameters fit for isobutane $+\mathrm{R}-125$ in NIST REFPROP $\left(\beta_{T}=1.0\right.$, $\left.\gamma_{T}=0.90538, \beta_{V}=1.0, \gamma_{V}=1.0036\right)$ were obtained in 2002 , and all of the experimental data at tempera- 1 tures below $293 \mathrm{~K}$ were collected in 2007 in the pub- 2 lication of Chen et al. (2007). This result highlights 3 as well that although the mixture models in NIST 4 REFPROP are in general the most accurate available 5 in the literature, they are only as reliable as the exper- 6 imental data that were available at the time the model 7 was developed. The conventional Peng-Robinson EoSs also demonstrates significant deviations from the ex- 9 perimental data. For the dew-point pressures (right 10 side of the figure), the mean error for REFPROP is 11 smallest in magnitude (1.2\%), followed by GC-VTPR 2 (4.0\%) and Peng-Robinson(18.2\%). Figure 3 shows 13 a few of the isotherms, highlighting that the largest 14 deviations are at low temperatures, below the range 15 where the PTXY data needed for model fitting in this 16 work are available.

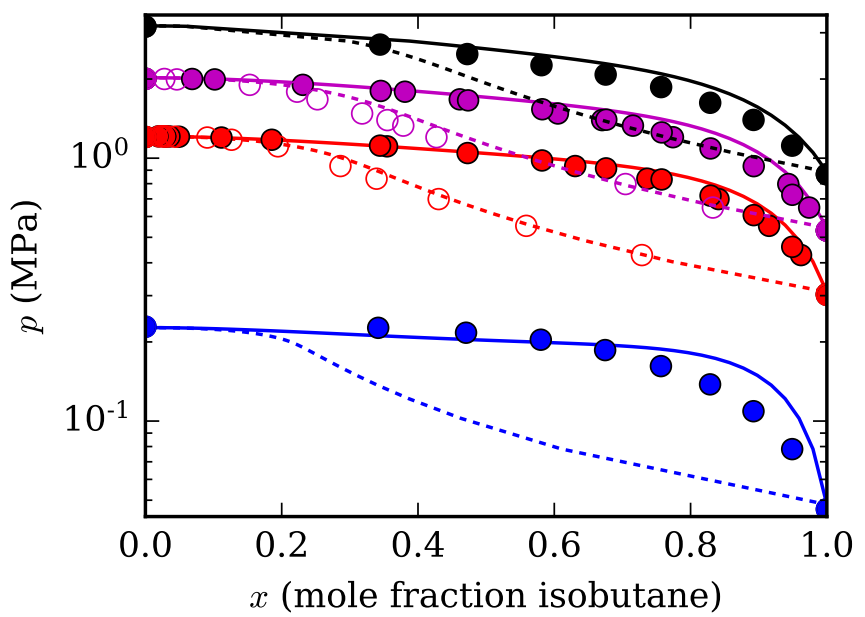

Figure 3: Selected pressure-composition isotherms (243.15, $293.15,313.15,333.15 \mathrm{~K}$ ) for the mixture isobutane $+\mathrm{R}-125$ versus the mole fraction of isobutane with the GC-VTPR model in this work: • bubble point experimental data; $\circ$ dew point experimental data; — calculated bubble point; - - - calculated dew point. Experimental data are from the literature (Chen et al., 2007, Lee et al. 2000

Finally, in Fig. 5 we present an overview of the results from the modeling of the bubble-point pressure and the bubble-point density. In each entry in the matrix a violin plot is presented, showing the distribution of the error for the property for the given binary pair. One would like to see a flat "pancake" distribution centered around $0 \%$ error. For many mixtures, the distribution is tightly clustered around zero. For other mixtures, a common systematic limitation of this fitting approach is seen: experimental PTXY data are available at higher pressures, and bubblepoint pressure measurements are available at lower pressures. This is the case described above for isobutane + R-125. In general, where wide-ranging PTXY data were available for a given binary mixture, the model is able to represent the data faithfully. The bubble-point density deviations are described below. 

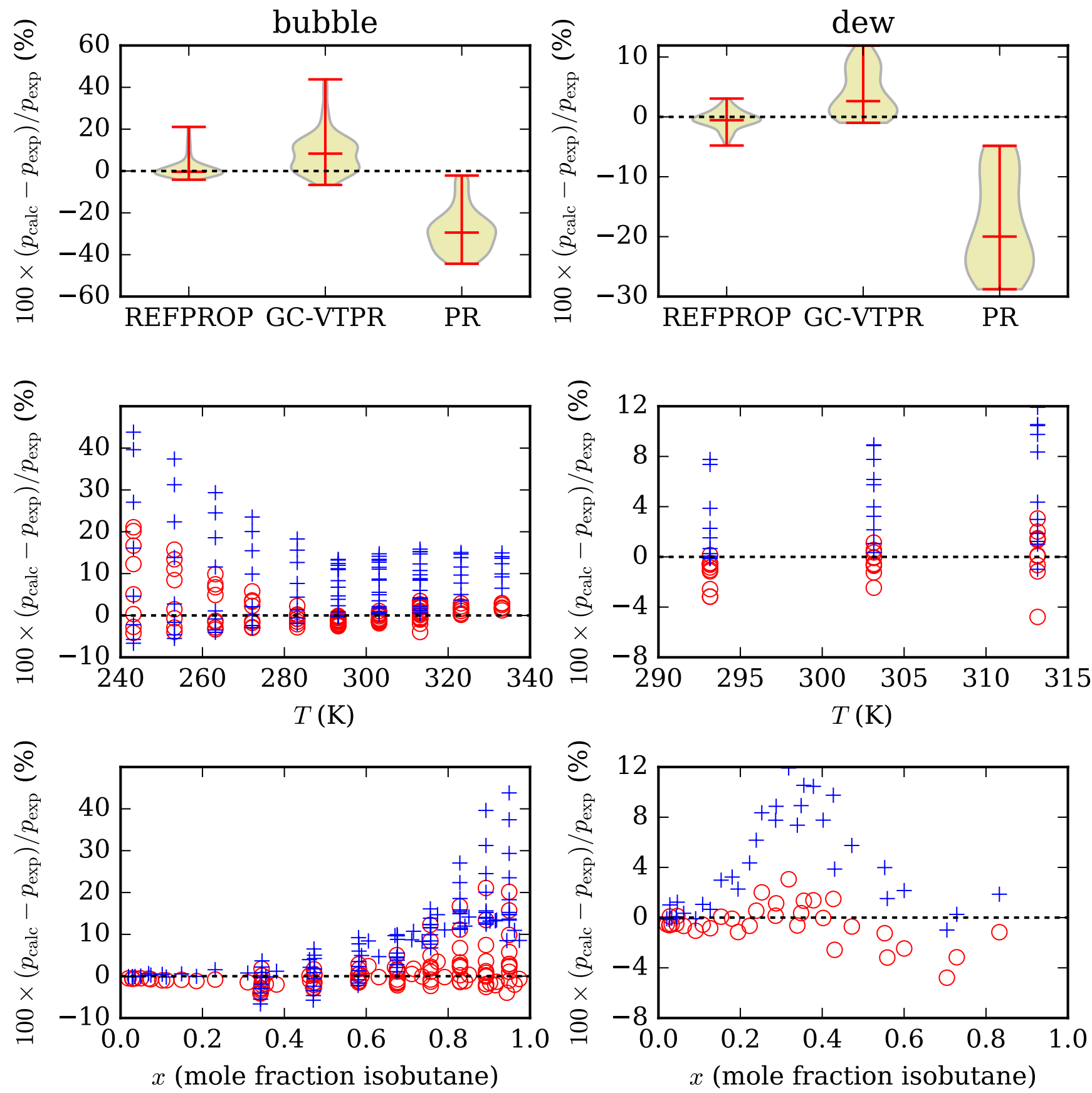

Figure 4: Deviation plots in saturation pressure for the mixture isobutane(1) + R-125(2) versus the mole fraction of isobutane and the temperature with the GC-VTPR model in this work. Experimental data are from the literature (Lee et al., 2000; Chen et al., 2007). Markers are given by o: REFPROP, +: GC-VTPR. The lower and upper bars in the violin plots represent the minimal and maximal values, respectively; the middle bar represents the median. 


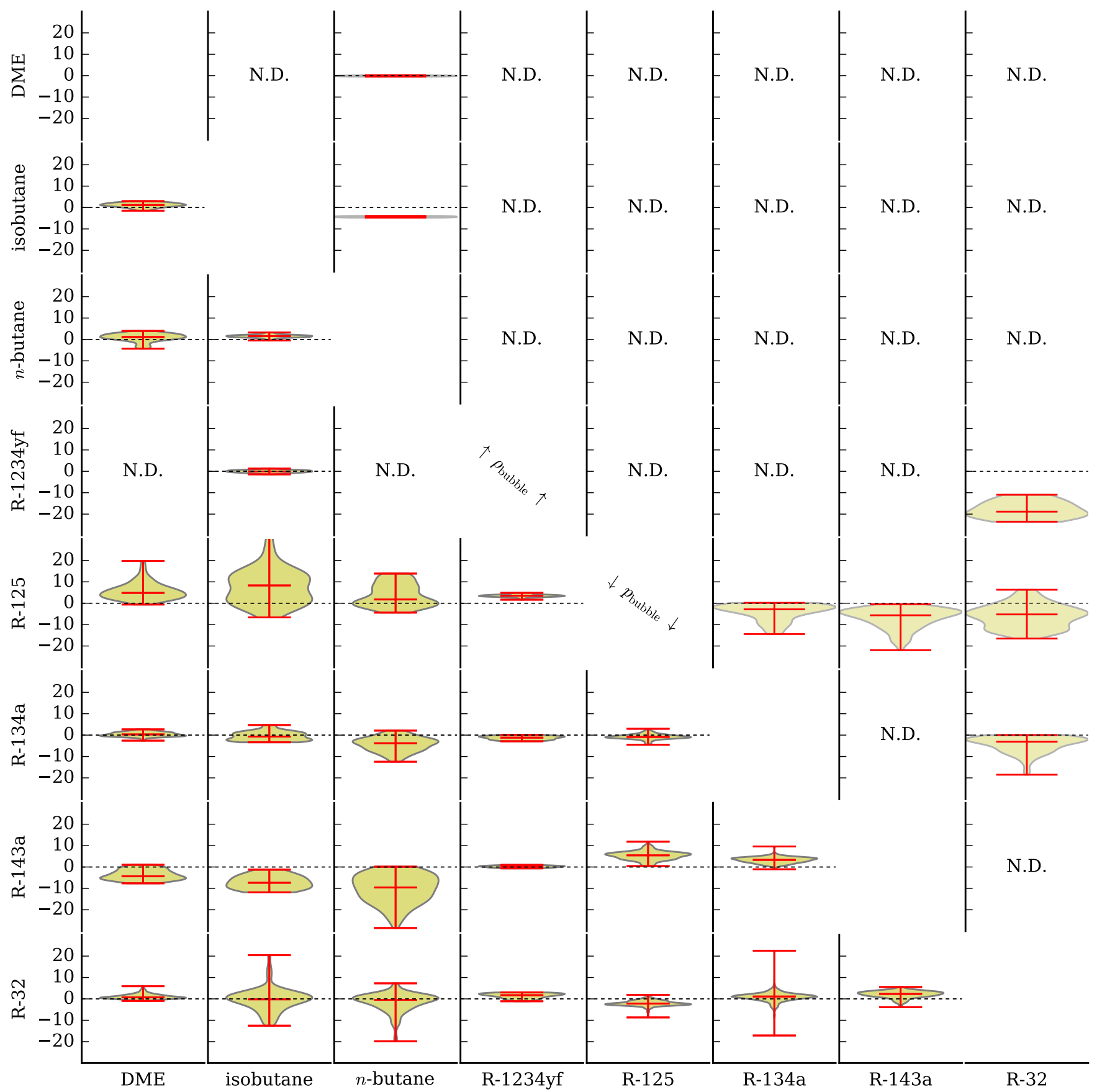

Figure 5: An overview of the goodness of fit for each binary pair, with violin plots shown for the deviations of bubble-point pressure and bubble-point density for the GC-VTPR model of this work as compared with the experimental data from the literature, as reported in ThermoDataEngine (details in the supplemental material). An entry of "N.D." indicates that no experimental data are available for the mixture. 


\subsection{Pure Fluid Saturated Liquid Densities}

The calculation of the volume translation parameter for the $\mathrm{i}$-th component $c_{i}$, defined in Eq. (10), was extended to mixtures through the use of a linear mole fraction weighting rule, as indicated in Eq. (16). Experimental values of the saturated liquid density at exactly $T_{\mathrm{r}}=0.7$ are in general not available, therefore the saturated liquid density at $T_{\mathrm{r}}=0.7$ was obtained through the use of a saturated liquid density ancillary equation, as in Outcalt and McLinden (1995), of the form $\rho_{l}=a_{1}+a_{2} \tau^{\beta_{1}}+a_{3} \tau^{\beta_{2}}+a_{4} \tau^{\beta_{3}}+$ $a_{5} \tau^{\frac{4}{3}}+a_{6} \tau^{2}+a_{7} \tau^{3}+a_{8} \tau^{4}$, where the coefficients $\beta_{1: 3}$ and $a_{1: 8}$ were fitted to experimental liquid density data of the pure fluids. The translation term for each pure fluid $c_{i}$, was obtained by calculating the density at a reduced temperature of $T_{\mathrm{r}}=T / T_{\mathrm{c}}=0.7$, as in $c_{i}=\left.\left(v_{\text {calc }}-v_{\text {anc }, \mathrm{i}}\right)\right|_{T_{\mathrm{r}}=0.7^{*}}$.

Figure 6 shows the percentage relative deviations between the densities obtained with the fitted value of $c_{i}$ for $n$-butane, and the experimental densities. The densities calculated by the non-volume-translated Peng-Robinson model are also shown for comparison purposes. As expected, after applying volume translation, the deviations for the saturated liquid density at $T_{\mathrm{r}}=0.7$ is near zero. The deviations in saturated liquid density are less than $0.5 \%$ in the temperature range $0.6 T_{\mathrm{c}}$ to $0.8 T_{\mathrm{c}}$. Equivalent figures for the rest of the pure fluids can be found in the supporting material; the reduced specific densities and the volume translation terms $c_{i}$ obtained through this process are also available in the supporting material.

\subsection{Mixture Saturated Liquid Densities}

In general, VLE density data for refrigerant mixtures are much less common than bubble-point and dew-point pressure data. This scarcity is largely driven by the difficulty of carrying out phase equilibrium density measurements as compared with vapor-liquid equilibrium measurements. As a result, there are only seven binary mixtures with any bubble-point density measurements. Figure 5 shows the same kind of violin plots as were generated for the bubble-point pressure. There are many systems with no phase

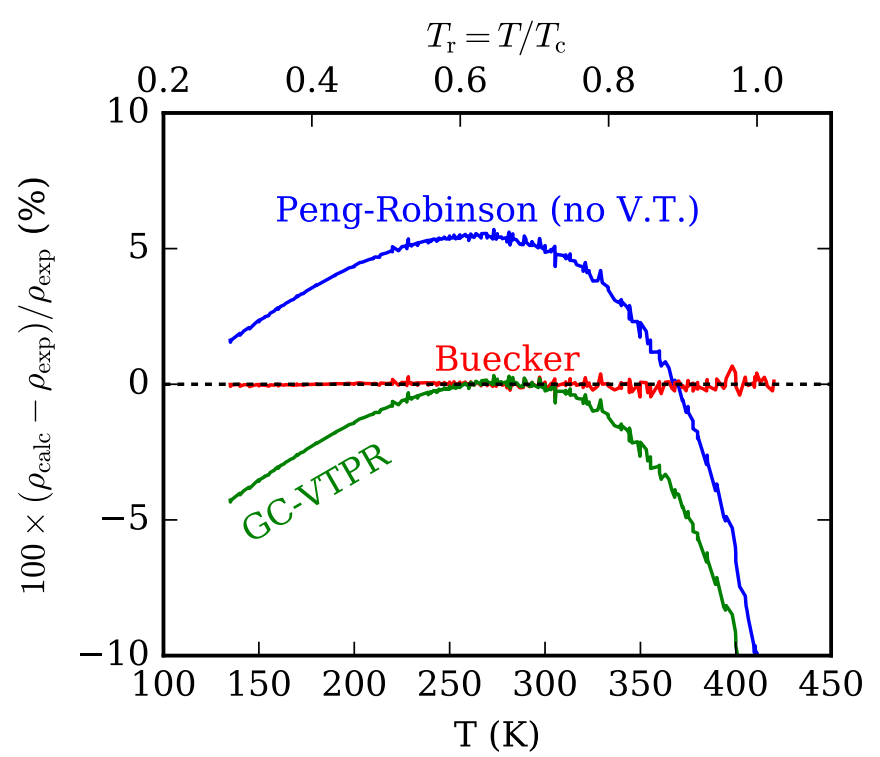

Figure 6: Relative deviations of the saturated liquid densities of $n$-butane from the multiparameter EOS of Buecker and Wagner (2006), GC-VTPR and PR compared with the experimental data from the literature (Dana et al., 1926, Coffin and Maass 1928, Kay, 1940, Benoliel, 1941, Carney, 1942a b, Legatski et al., 1942; Cragoe, 1943, Olds et al., 1944; Prengle et al., 1948; Klosek and McKinley, 1968, Sliwinski. 1969; Haynes and Hiza, 1976, McClune, 1976, Haynes and Hiza, 1977, Calado et al., 1978; Orrit and Laupretre, 1978; Thompson and Miller, 1980; Hsu et al., 1985; Kaminishi et al., 1988; Niesen, 1989; Vasserman et al., 1989, Holcomb et al., 1995; Kumagai and Takahashi, 1995; Dahlhoff et al., 2000, Glos et al., 2004, Kayukawa et al. 2005; Miyamoto and Uematsu, 2007). 
equilibrium density measurements. In general, bubble $\rightarrow$ point density measurements are carried out prior to 38 dew-point density measurements for a given mixture, 39 therefore there are only 5 systems for which any dew- 40 point density measurements are available. Only the ${ }_{41}$ bubble-point density deviation plots are shown in this 42 figure.

The deviations in bubble-point density are in gen- 44 eral larger in relative terms than the deviations in 45 bubble-point pressure; this is a result of a number ${ }_{46}$ of compounding errors. The first error contribution ${ }_{47}$ arises from the UNIFAC contribution; if the UNIFAC contribution shifts the phase equilibrium in a dele- ${ }_{48}$ terious direction, the non-volume-translated equilibrium densities may also be perturbed. The volume ${ }^{49}$ translation is then applied after the phase equilibrium ${ }^{50}$ calculation, but as is evident in Fig. 6, the volume ${ }^{51}$ translation has a rather small range in reduced tem- ${ }^{52}$ perature where it is particularly effective. For state ${ }^{53}$ points away from $T_{\mathrm{r}}=0.7$ for the pure fluids in the $e^{54}$ mixture, the volume translation does not necessarily ${ }^{55}$ compensate in the appropriate direction. The poor ${ }^{56}$ matching of volume translation constants for pure ${ }^{57}$ fluids in the mixture can be especially problematic ${ }^{58}$ for mixtures where the critical temperatures of the ${ }^{59}$ components are very different, although for the re- ${ }^{60}$ frigerant mixtures studied in this work the critical $^{61}$ temperatures are relatively similar. The inclusion of ${ }^{62}$ Péneloux-style volume translation does not always ${ }^{63}$ improve the representation of liquid-phase densities, ${ }^{64}$ and at low and high temperatures, the volume trans- ${ }^{65}$ lation can significantly degrade the prediction of liquide like densities. On the other hand, much of the interest for industrial applications is in the temperature range near $0.7 T_{\mathrm{c}}$, so volume translation can be worthwhile depending on the particulars of the modeling prob- ${ }_{70}^{69}$ lem to be solved.

Figure 7 shows deviation plots for the bubblepoint densities for the mixture of R-143a + R-125. This is a mixture with one of the worst representations of the bubble-point densities in Fig. 5, so it is instructive to better understand this system. The pri- 75 mary reason for the poor representation of the phase 76 equilibrium densities is that the available densities are not in the vicinity of $0.7 T_{\mathrm{c}}$ of the pure components, the temperature at which the volume translation has been tuned. The deviations in bubble-point density increase as the temperature increases away from $0.7 T_{\mathrm{c}}$ of the pure components, while there is minimal dependence on the composition of the mixture. Other authors (Le Guennec et al. 2016b) also note that away from the point at which the volume translation has been tuned the representation of densities is significantly worse.

\section{Conclusions}

In this work, the group contribution volume translated Peng Robinson equation of state (GC-VTPR EoS) was applied to a set of constituent fluids forming commercial refrigerant mixtures. The accuracy of this equation of state was evaluated by analyzing the relative deviations of the estimated values versus experimental data of saturation pressures and saturated liquid and vapor densities. The performance of the GC-VTPR EoS was also compared to that of the standard Peng-Robinson equation of state and the multi-fluid Helmholtz energy equation of state implemented in NIST REFPROP 10(Lemmon et al., 2018). This comparison allowed for an analysis of the potential improvements in cubic equations of state through the use of volume translation and an excess Gibbs energy group contribution term.

Based on the results of this analysis, the following conclusions were drawn:

- The GC-VTPR EoS yields competitive accuracy with NIST REFPROP for the saturation pressure of mixtures containing components with similar molecular structure. As the difference between the molecular structure of the components increases, the GC-VTPR EoS tends to yield larger deviations than REFPROP. This is observed also for the Peng-Robinson EoS.

- The predicted liquid density values are strongly influenced by the application of volume trans- 

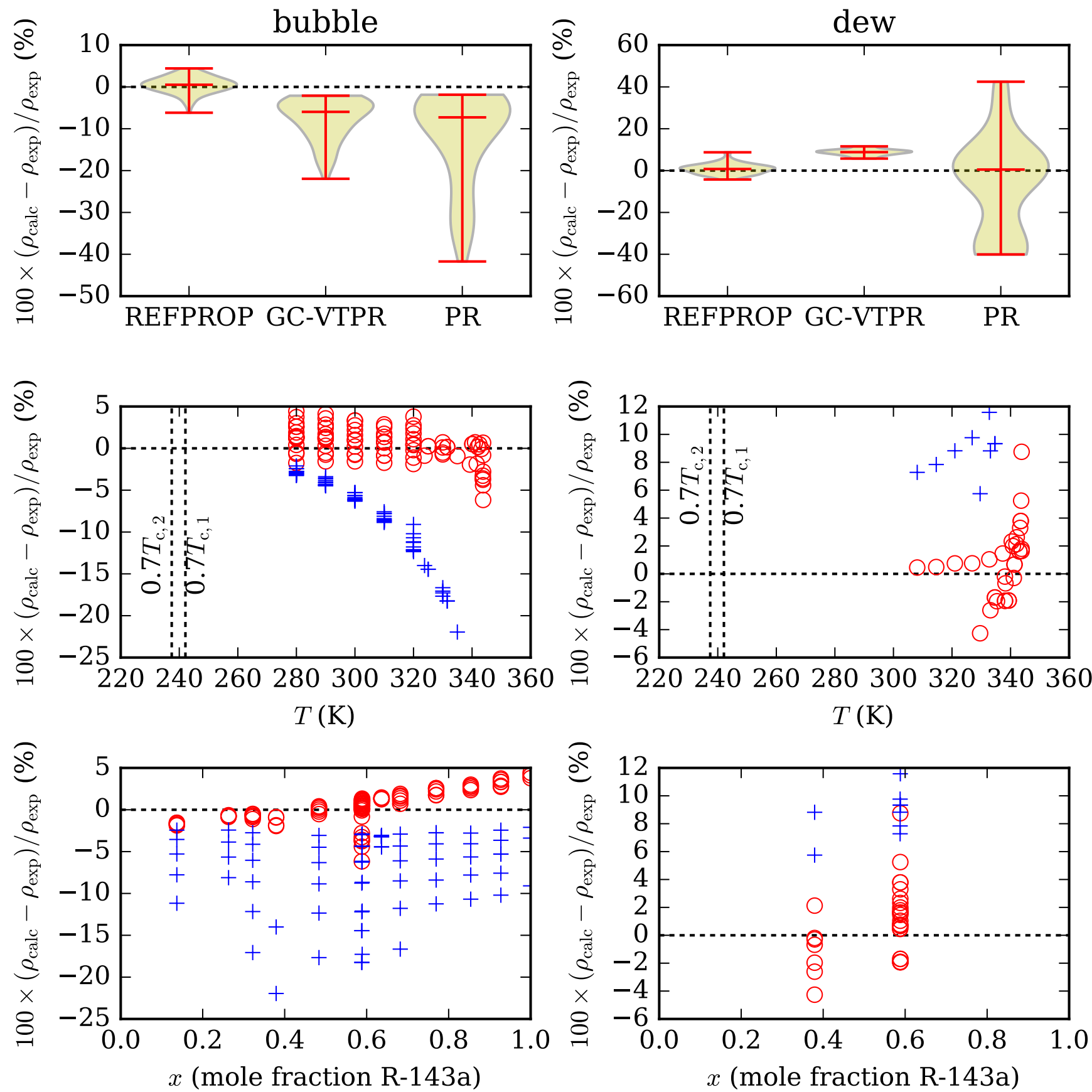

Figure 7: Deviation plots in saturation densities for the mixture R-143a (1) + R-125 (2) versus the mole fraction of R-143a and the temperature with the models investigated in this work. Markers are given by o: REFPROP, +: GC-VTPR. Experimental data points for which the vapor-liquid equilibrium calculations failed are not shown. The lower and upper bars in the violin plots represent the minimal and maximal values, respectively; the middle bar represents the median. Experimental data are from the literature (Ikeda and Higashi, 1995: Widiatmo et al., 1995, Fujimine et al., 1999, Higashi, 1999b; Kishizawa et al., 1999, Uchida et al., 1999). 
lation; this is by design as the volume translation is intended to "repair" the saturated liquid densities. This volume translation parameter may benefit from a temperature dependence and an improved mixing rule that considers the size difference between the molecules.

- The GC-VTPR EoS evaluated in this work offers competitive results in terms of accuracy with other EoS and could be used for the study of new refrigerant mixtures for which insufficient experimental data are available to fit the highly accurate (and complicated) fluid models used in NIST REFPROP. Moreover, im- ${ }_{34}$ provement of the volume translation and mix- ${ }_{35}$ ing rules provides opportunities to further improve the accuracy of this modeling framework.

\section{Acknowledgements}

The authors thank Jorrit Wronski (IPU) for coding support, Jens Abildskov (DTU) for the discussions on the fitting of activity coefficients. Jonathan Welliquet thanks the Erasmus + project who provided financial support for his internship at DTU. Maria E. Mondejar acknowledges the financial support from ${ }^{36}$ the European Union's Horizon 2020 research and in- ${ }_{37}$ novation programme with a Marie Skłodowska-Curie 38 Fellowship under grant agreement No 704201 with ${ }^{39}$ the project NanoORC (www.nanoorc.mek.dtu.dk). ${ }_{41}^{40}$

\section{Appendix A. Parameters for the Twu $\boldsymbol{\alpha}$ function}

The parameters $L, M$ and $N$ for the Twu $\alpha$ func- 45 tion (see Eq. 12) were optimized and tabulated by ${ }^{46}$ Bell et al. (2018) for 2570 fluids. Table A.4 presents ${ }^{47}$ the values of the parameters used in this work.

\section{Appendix B. Interaction parameters for the term ${ }^{51}$ $a_{m n}$.

The interaction parameters $a_{m n}$ for Eq. (28) are ${ }^{54}$ collected in Table B.5. The parameters for $a_{45}$ and ${ }^{55}$ $a_{54}$ are unknown (and set to zero) because these groups ${ }_{57}^{56}$
Table A.4: Consistent coefficients for the Twu $\alpha$ function for the fluids considered in this work. All coefficients have been taken from the work of Bell et al. (2018)

\begin{tabular}{llll}
\hline Fluid & $\mathrm{L}$ & $\mathrm{M}$ & $\mathrm{N}$ \\
\hline n-butane & 0.4652 & 0.8475 & 1.2010 \\
isobutane & 1.1121 & 0.9991 & 0.5440 \\
R-143a & 0.2450 & 0.8491 & 2.1298 \\
R-125 & 1.0845 & 0.9986 & 0.7413 \\
R-134a & 0.3064 & 0.8298 & 2.0112 \\
R-1234yf & 0.1659 & 0.8437 & 2.6526 \\
R-32 & 0.3436 & 0.8546 & 1.7906 \\
DME & 0.8312 & 0.8881 & 0.7446 \\
\hline
\end{tabular}

were not present in any of the experimental data included in this study.

Table B.5: Interaction parameters $a_{m n}$ in K.

\begin{tabular}{|c|c|c|c|c|c|c|}
\hline $\mathrm{mgi}$ & & $\mathrm{n}=1$ & 2 & 3 & 4 & 5 \\
\hline \multirow[t]{5}{*}{$\mathrm{m}=$} & 1 & 0 & 197.06 & 268.17 & 69.746 & 17.476 \\
\hline & 2 & 2.2679 & 0 & -9.3253 & -96.001 & -330.51 \\
\hline & 3 & 75.107 & 29.518 & 0 & 83.803 & -78.799 \\
\hline & 4 & -4.7829 & 269.44 & 206.02 & 0 & 0 \\
\hline & 5 & 540.81 & 999.99 & 35.719 & 0 & 0 \\
\hline
\end{tabular}

\section{References}

Abrams, D. S., Prausnitz, J. M., 1975. Statistical Thermodynamics of Liquid Mixtures: A New Expression for the Excess Gibbs Energy of Partly or Completely Miscible Systems. AIChE J. 21 (1), 116-128.

Ahlers, J., Gmehling, J., 2002a. Development of a universal group contribution equation of state. 2. Prediction of vaporliquid equilibria for asymmetric systems. Ind. Eng. Chem. Res. 41 (14), 3489-3498.

Ahlers, J., Gmehling, J., 2002b. Development of a universal group contribution equation of state III. Prediction of vaporliquid equilibria, excess enthalpies, and activity coefficients at infinite dilution with the VTPR model. Ind. Eng. Chem. Res. 41 (23), 5890-5899.

ASHRAE, 2016. ANSI/ASHRAE Standard 34-2016 Designation and Safety Classification of Refrigerants.

Bell, I. H., Jäger, A., 2016. Helmholtz Energy Transformations of Common Cubic Equations of State for Use with Pure Fluids and Mixtures. J. Res. Nat. Inst. Stand. Technol. 121, 238.

Bell, I. H., Satyro, M., Lemmon, E. W., 2018. Consistent Twu Parameters for More than 2500 Pure Fluids from Critically Evaluated Experimental Data. J. Chem. Eng. Data. 
Bell, I. H., Wronski, J., Quoilin, S., Lemort, V., 2014. Pure and 41 Pseudo-pure Fluid Thermophysical Property Evaluation and 42 the Open-Source Thermophysical Property Library Cool- 43 Prop. Ind. Eng. Chem. Res. 53 (6), 2498-2508.

Ben Adamson, B., Airah, M., 1998. Dimethyl ether as an R12 45 replacement. In: Proceeding of IIF-IIR conference (Com- 46 missions B1, B2, E1 and E2), Osslo, Norway. pp. 610-17. 47

Benmansour, S., Richon, D., 1999. Vapor-Liquid Equilibria 48 and Densities of the Binary Refrigerant Mixture Composed 49 of Pentafluoroethane (R 125) and 1,1,1,2-Tetrafluoroethane 50 (R 134a) at Temperatures Between $253 \mathrm{~K}$ and $303 \mathrm{~K}$ and 51 Pressures up to $20 \mathrm{MPa}$ (10402 data points). Experimental 52 Data and Correlations,. ELDATA: The International Elec- 53 tronic Journal of Physico-Chemical Data 5, 117-126.

Benoliel, R. W., 1941. Some Physical Constants of Seven Four- 55 Carbon-Atom Hydrocarbons and Neopentane. Ph.D. thesis, 56 Pennsylvania State University.

Bobbo, S., Stryjek, R., Elvassore, N., Bertucco, A., 1998. A re- 58 circulation apparatus for vapor-liquid equilibrium measure- 59 ments of refrigerants. Binary mixtures of R600a, R134a and 60 R236fa. Fluid Phase Equilib. 150-151, 343-352.

Bondi, A., 1968. Physical Properties of Molecular Liquids, 62 Crystals, and Glasses. Wiley, New York.

Buecker, D., Wagner, W., 2006. Reference Equations of State 64 for the Thermodynamic Properties of Fluid Phase n-Butane 65 and Isobutane. J. Phys. Chem. Ref. Data 35 (2), 929-1019. 66

Calado, J. C. G., McLure, I. A., Soares, V. A. M., 1978. Sur- 67 face Tension for Octafluorocyclobutane, n-Butane and their 68 Mixtures from $233 \mathrm{~K}$ to $254 \mathrm{~K}$, and Vapor Pressure, Excess 69 Gibbs Function, and Excess Volume for the Mixtures at 23370 K. Fluid Phase Equilib. 2, 199-213.

Carney, B. R., 1942a. Density of Liquified Petroleum Gas Hy- 72 drocarbons. Hydrocarbon Process. 21, 274.

73

Carney, B. R., 1942b. Density of Liquified Petroleum Gas Hy- 74 drocarbons, Their Mixtures and Three Natural Gasolines. 75 Hydrocarbon Process. 21, 84.

76

Chen, J., Fischer, K., Gmehling, J., 2002. Modification of 77 PSRK mixing rules and results for vapor-liquid equilibria, 78 enthalpy of mixing and activity coefficients at infinite dilu- 79 tion. Fluid Phase Equilib. 200 (2), 411-429.

80

Chen, J.-X., Chen, Z., Hu, P., Jiang, B., Li, Z.-H., 2007. Vapor- 81 Liquid Equilibria for the Binary System Pentafluoroethane 82 (HFC-125) + Isobutane (HC-600a) at Temperatures from 83 (243.15 to 333.15) K. J. Chem. Eng. Data 52, 2159-2162. 84

Coffin, C. C., Maass, O., 1928. The Preparation and Physical 85 Properties of .alpha.-,.beta.- and .gamma.-Butylene and Nor- 86 mal and Isobutane. J. Am. Chem. Soc. 50, 1427-1437. 87

Cragoe, C. S., 1943. Tech. Rep. LC-736, Natl. Bur. Stand. (U. 88 S.).

89

Dahlhoff, G., Pfennig, A., Hammer, H., Oorschot, M. v., 2000. 90 Vapor-Liquid Equilibria in Quaternary Mixtures of Dimethyl 91
Ether + n-Butane + Ethanol + Water. J. Chem. Eng. Data 45, 887-892.

Dana, L. I., Jenkins, A. C., Burdick, H. E., Timm, R. C., 1926. Thermodynamic Properties of Butane, Isobutane, and Propane. Refrig. Eng. 12, 387.

Fredenslund, A., Jones, R. L., Prausnitz, J. M., 1975. Groupcontribution estimation of activity coefficients in nonideal liquid mixtures. AIChE Journal 21 (6), 1086-1099.

Frey, K., Augustine, C., Ciccolini, R. P., Paap, S., Modell, M., Tester, J., 2007. Volume translation in equations of state as a means of accurate property estimation. Fluid Phase Equilib. 260 (2), 316-325.

Fujimine, T., Sato, H., Watanabe, K., 1999. Bubble-Point Pressures and Saturated- and Compressed-Liquid Densities of the Binary R-125 + R-143a System. Int. J. Thermophys. 20, 911-922.

Glos, S., Kleinrahm, R., Wagner, W., 2004. Measurement of the (p,.rho., $\mathrm{T})$ relation of propane, propylene, $\mathrm{n}$-butane, and isobutane in the temperature range from (95 to 340) $\mathrm{K}$ at pressures up to $12 \mathrm{MPa}$ using an accurate two-sinker densimeter. J. Chem. Thermodyn. 36, 1037-1059.

Gmehling, J., 1985. Dortmund Data Bank-Basis for the development of prediction methods. CODATA Bulletin (58), 5664.

Haynes, W. M., Hiza, M. J., 1976. Orthobaric liquid densities of normal butane from 135 to $300 \mathrm{~K}$ as determined with a magnetic suspension densimeter. Adv. Cryog. Eng. 21, 51621.

Haynes, W. M., Hiza, M. J., 1977. Measurements of the Orthobaric Liquid Densities of Methane, Ethane, Propane, Isobutane, and Normal Butane. J. Chem. Thermodyn. 9, 179-187.

Higashi, Y., 1999a. Vapor- Liquid Equilibrium, Coexistence Curve, and Critical Locus for Pentafluoroethane + 1,1,1,2Tetrafluoroethane (R125/R134a). J. Chem. Eng. Data 44, 328-332.

Higashi, Y., 1999b. Vapor-Liquid Equilibrium, Coexistence Curve, and Critical Locus for Pentafluoroethane + 1,1,1Trifluoroethane (R125/R143a). J. Chem. Eng. Data 44, 333337.

Higuchi, M., Higashi, Y., 1995. Measurements of the VaporLiquid Equilibrium for Binary R-125/134a,. In: Proc. 16th Japan Symp. Thermophys. Prop. pp. 5-8.

Holcomb, C., Magee, J. W., Scott, J. L., Outcalt, S. L., Haynes, W. M., 1998. Selected Thermodynamic Properties for Mixtures of R-32 R-125 R-134A R-143A R-41 R-290 and R744. Tech. Rep. Technical Note 1397, NIST.

Holcomb, C. D., Magee, J. W., Haynes, W. M., 1995. Gas Processors Association Project. Tech. Rep. 916, Research Report RR-147.

Hsu, J., Nagarajan, N., Robinson Jr., R. L., 1985. Equilibrium Phase Compositions, Phase Densities and Interfacial Ten- 
sions for $\mathrm{CO} 2+$ Hydrocarbon Systems. 1. CO2 + n-Butane. 41 J. Chem. Eng. Data 30, 485-491.

Ikeda, T., Higashi, Y., 1995. Determination of the critical pa- 43 rameters for new refrigerant R-507 and R-407C. In: 16th 44 Japan Symp. Thermophys. Prop. pp. 169-172.

ISO 817:2014(en), 2000. Refrigerants - Designation and safety 46 classification. Standard, International Organization for Stan- 47 dardization, Geneva, $\mathrm{CH}$.

\section{8}

Jaubert, J.-N., Mutelet, F., 2004. Vle predictions with the peng-49 robinson equation of state and temperature dependent kij cal- 50 culated through a group contribution method. Fluid Phase 51 Equilibria 224 (2), 285-304.

52

Jaubert, J.-N., Privat, R., Guennec, Y. L., Coniglio, L., 2016. 53 Note on the properties altered by application of a Péneloux-54 type volume translation to an equation of state. Fluid Phase 55 Equilib. 419, 88-95.

Ji, W.-R., Lempe, D., 1997. Density improvement of the SRK 57 equation of state. Fluid Phase Equilibria 130 (1-2), 49-63. 58

Kaminishi, G.-I., Yokoyama, C., Takahashi, S., 1988. Saturated 59 liquid densities of n-butane-isobutane, n-butane-propane, 60 isobutane-propane and n-butane-isobutane-propane mix-61 tures. Sekiyu Gakkaishi 31, 433-8.

62

Kato, R., Nishiumi, H., 2006. Vapor liquid equilibria and criti- 63 cal loci of binary and ternary systems composed of $\mathrm{CH} 2 \mathrm{~F} 2,64$ C2HF5 and C2H2F4. Fluid Phase Equilib. 249, 140-146. 65

Kay, W. B., 1940. Pressure-Volume-Temperature Relations for 66 n-Butane. Ind. Eng. Chem. 32, 358-360.

\author{
67
}

Kayukawa, Y., Hasumoto, M., Kano, Y., Watanabe, K., 2005.68 Liquid-Phase Thermodynamic Properties for Propane (1), n- 69 Butane (2), and Isobutane (3). J. Chem. Eng. Data 50, 556-70 564.

Kim, C. N., Park, Y. M., 1999. Vapor-liquid equilibrium of 72 HFC-32/134 a and HFC-125/134a systems. Int. J. Thermo- 73 phys. 20, 519-530.

Kishizawa, G., Sato, H., Watanabe, K., 1999. Measurements of 75 Saturation Densities in Critical Region and Critical Loci for 76 Binary R-32/125 and R-125/143a Systems. Int. J. Thermo- 77 phys. 20, 923-932.

\section{8}

Kleemiss, M., 1997. Fortschrittsberichte VDI: Thermodynamic 79 Properties of Two Ternary Refrigerant Mixtures: Measure- 80 ments and Equations of State. Tech. Rep. Reihe 19 Nr. 98, 81 VDI Verlag GmbH.

Klosek, J., McKinley, C., 1968. Densities of LNG and of Loq 83 Molecular Weight Hydrocarbons. In: Proc. First Int. Confer- 84 ence on LNG.

Kobayashi, M., Nishiumi, H., 1998. Vapor-liquid equilibria 86 for the pure, binary and ternary systems containing HFC32, 87 HFC125 and HFC134a. Fluid Phase Equilib. 144, 191-202. 88

Kumagai, A., Takahashi, S., 1995. Viscosity and density of liq- 89 uid mixtures of n-alkanes with squalane. Int. J. Thermophys. 90 $16,773-779$.
Kunz, O., Klimeck, R., Wagner, W., Jaeschke, M., 2007. The GERG-2004 Wide-Range Equation of State for Natural Gases and Other Mixtures. VDI Verlag GmbH.

Le Guennec, Y., Lasala, S., Privat, R., Jaubert, J. N., $2016 \mathrm{a}$. A consistency test for alpha-functions of cubic equations of state. Fluid Phase Equilib. 427, 513-538.

Le Guennec, Y., Privat, R., Jaubert, J.-N., 2016b. Development of the translated-consistent tc-PR and tc-RK cubic equations of state for a safe and accurate prediction of Volumetric, energetic and saturation properties of pure compounds in the sub- and super-critical domains. Fluid Phase Equilibria 429, 301-312.

Lee, B. G., Park, J. Y., Lim, J. S., Lee, Y. W., Lee, C. H., 2000. Vapor-liquid equilibria for isobutane + pentafluoroethane (HFC-125) at 293.15 to $313.15 \mathrm{~K}$ and $+1,1,1,2,3,3,3-$ heptafluoropropane (HFC-227ea) at 303.15 to $323.15 \mathrm{~K}$. J. Chem. Eng. Data 45, 760-763.

Legatski, T., Nelson, W., Dean, M., Fruit, L., 1942. Densities of Liquefied Petroleum Gases,. Ind. Eng. Chem. 34, 12401243.

Lemmon, E. W., Bell, I. H., Huber, M. L., McLinden, M. O., 2018. NIST Standard Reference Database 23: Reference Fluid Thermodynamic and Transport Properties-REFPROP, Version 10.0, National Institute of Standards and Technology. http://www.nist.gov/srd/nist23.cfm.

Lim, J. S., Park, J. Y., Lee, B. G., Lee, Y. W., Kim, J. D., 2000. Reply to Comments by Stanislaw K. Malanowski and Roman Stryjek on J. Chem. Eng. Data 1999, 44, 1226-1230. J. Chem. Eng. Data 45, 1219-1221.

Lopez-Echeverry, J. S., Reif-Acherman, S., Araujo-Lopez, E., 2017. Peng-Robinson equation of state: 40 years through cubics. Fluid Phase Equilib. 447, 39-71.

Mathias, P. M., Copeman, T. W., 1983. Extension of the PengRobinson equation of state to complex mixtures: evaluation of the various forms of the local composition concept. Fluid Phase Equilib. 13, 91-108.

McClune, C. R., 1976. Measurements of the Densities of Liquefied Hydrocarbons from 93 to 173 K. Cryogenics 16, 289 95.

Miyamoto, H., Uematsu, M., 2007. Measurements of vapour pressures and saturated-liquid densities for $\mathrm{n}$-butane at $\mathrm{T}=$ (280 to 424) K. J. Chem. Thermodyn. 39, 827-832.

Mota-Babiloni, A., Navarro-Esbrí, J., Barragán-Cervera, Á., Molés, F., Peris, B., 2015. Analysis based on EU Regulation No 517/2014 of new HFC/HFO mixtures as alternatives of high GWP refrigerants in refrigeration and HVAC systems. Int. J. Refrig 52, 21-31.

Nagel, M., Bier, K., 1995. Vapor-liquid equilibrium of ternary mixtures of the refrigerants R32, R125 and R134a. Int. J. Refrig. 18, 534-43.

Niesen, V. G., 1989. (Vapor + liquid) equilibria and coexisting 
densities of (carbon dioxide + n-butane) at 311 to 395 K. J. 41 Chem. Thermodyn. 21, 915-923.

Nishiumi, H., Ohno, T., 2000. High Pressure Vapor-liquid Equi- 43 libria and Critical Loci for the HFC125-HFC134a System. 44 Korean J. Chem. Eng. 17, 668-671.

Olds, R. H., Reamer, H. H., Sage, B. H., Lacey, W. N., 1944. 46 Phase Equilibria in Hydrocarbon Systems. Volumetric Be- 47 haviour of n-Butane. Ind. Eng. Chem. 36, 282.

\section{8}

Orrit, J. E., Laupretre, J. M., 1978. Density of liquefied natural 49 gas components. Adv. Cryog. Eng. 23, 573.

Outcalt, S., McLinden, M. O., 1995. Equations of State for the 51 Thermodynamic Properties of R32 ( Difluoromethane ) and 52 R 125 ( Pentafluoroethane ). Int. J. Thermophys. 32 (I). 53

Péneloux, A., Rauzy, E., Fréze, R., 1982. A consistent correc-115 tion for Redlich-Kwong-Soave Volumes. Fluid Phase Equir-116 lib. 8 (1), 7-23.

1117

Peng, D.-Y., Robinson, D. B., 1976. A New Two-Constantt18 Equation of State. Ind. Eng. Chem. Fundam. 15 (1), 59-64.1119

Poling, B. E., Prausnitz, J. M., O'Connell, J. P., 2001. The Prop-120 erties of Gases and Liquids, 5th edition. McGraw Hill. 1121

Prengle, H. W., Greenhaus, L. R., York, R., 1948. Thermody-122 namic properties of n-Butane. Chem. Eng. Prog. 44, 863-81123

Privat, R., Jaubert, J.-N., Guennec, Y. L., 2016. Incorporation 24 of a volume translation in an equation of state for fluid mix-125 tures: which combining rule? which effect on properties offi26 mixing? Fluid Phase Equilib. 427, 414-420.

1127

Qian, J.-W., Privat, R., Jaubert, J.-N., Coquelet, C., Ramjuger-128 nath, D., 2017. Fluid-phase-equilibrium prediction offi29 fluorocompound-containing binary systems with the predic-130 tive e-ppr78 model. International Journal of Refrigeration 31 $73,65-90$.

URL http://www.sciencedirect.com/science/ article/pii/S0140700716302936

Schmid, B., Gmehling, J., 2012. Revised parameters and typical results of the VTPR group contribution equation of state. Fluid Phase Equilib. 317, 110-126.

Schmid, B., Gmehling, J., 2016. Present status of the group contribution equation of state VTPR and typical applications for process development. Fluid Phase Equilib. 425, 443-450.

Schmid, B., Schedemann, A., Gmehling, J., 2014. Extension of the VTPR group contribution equation of state: Group interaction parameters for additional 192 group combinations and typical results. Ind. Eng. Chem. Res. 53 (8), 3393-3405.

Sliwinski, P., 1969. The lorentz-lorenz function of gaseous and liquid ethane, propane and butane. Z. Phys. Chem. (Munich) 63, 263-79.

Soave, G., 1972. Equilibrium Constants from a Modified Redlich-Kwong Equation of State. Chem. Eng. Sci. 27, 1197-1203.

Storn, R., Price, K., 1997. Differential Evolution - A Simple and Efficient Heuristic for global Optimization over Contin- uous Spaces. J. Global Opt. 11.

Thompson, R. T., Miller, R. C., 1980. Densities and Dieletric Constants of LPG Components and Mixtures at Cryogenic Storage Conditions. Adv. Cryog. Eng. 26, 698.

Twu, C. H., Bluck, D., Cunningham, J. R., Coon, J. E., 1991. A cubic equation of state with a new alpha function and a new mixing rule. Fluid Phase Equilib. 69, 33-50.

Twu, C. H., Coon, J. E., Cunningham, J. R., 1995. A new generalized alpha function for a cubic equation of state Part 1. Peng-Robinson equation. Fluid Phase Equilib. 105 (1), 4959.

Uchida, H., Sato, H., Watanabe, K., 1999. Measurements of Gaseous PVTx Properties and Saturated Vapor Densities of Refrigerant Mixture R-125+R-143a. Int. J. Thermophys. 20, 97-106.

Valderrama, J. O., 2003. The State of the Cubic Equations of State. Ind. Eng. Chem. Res. 42 (8), 1603-1618.

van der Waals, J. D., 1873. Over de Continuiteit van den Gasen Vloeistoftoestand. Ph.D. thesis, University of Leiden.

Vasserman, A. A., Khasilev, I. P., Cymarnyi, V. A., 1989. Tables of recommended data. N-butane. Pressure and density of liquid and gas at saturation. Tech. Rep. 604-kk, VNIIKI.

Wei, Y. S., Sadus, R. J., 2000. Equations of State for the Calculation of Fluid-Phase Equilibria. AIChE J. 46 (1), 169-196.

Widiatmo, J. V., Fujimine, T., Sato, H., Watanabe, K., 1997. Liquid Densities of Alternative Refrigerants Blended with Difluoromethane, Pentafluoroethane, and 1,1,1,2Tetrafluoroethane. J. Chem. Eng. Data 42, 270-277.

Widiatmo, J. V., Sato, H., Watanabe, K., 1995. Bubble-point pressures and liquid densities of binary R-125 + R-143a system. Int. J. Thermophys. 16, 801-810. 